\title{
Recovery characteristics of different tube materials in relation to combustion products
}

\author{
M. Karjalainen ${ }^{1}$ (1) $\cdot$ A. Kontunen ${ }^{1} \cdot$ M. Mäkelä ${ }^{1} \cdot$ O. Anttalainen ${ }^{2} \cdot$ A. Vehkaoja $^{1} \cdot$ N. Oksala $^{1,3} \cdot$ A. Roine ${ }^{1}$
}

Received: 29 May 2020 / Revised: 1 July 2020 / Accepted: 2 July 2020 / Published online: 22 July 2020

(C) The Author(s) 2020

\begin{abstract}
Common challenge in gas analyzers such as Ion Mobility Spectrometers (IMS) integrated into a measurement system is the reduced analysis speed that is partially limited by the temporal carry-over of sample molecules. It is caused by adsorption and absorption of the molecules into the gas tubes of the analyzer. We studied the recovery times of common tube materials: polyether ether ketone (PEEK), polytetrafluoroethylene (PTFE), fluorinated ethylene propylene (FEP), polyethylene (PE), steel 316 L, parylene $\mathrm{C}$ coated steel and Silconert ${ }^{\circledR}$ coated steel from organic combustion products. The tests were performed in two temperatures, at $25{ }^{\circ} \mathrm{C}$ and at $70{ }^{\circ} \mathrm{C}$. In addition, detailed analysis was performed for PTFE tube material at $33,50,70$ and $100{ }^{\circ} \mathrm{C}$ to observe the temperature relation of desorption. Uncoated steel was found to have the best performance in increased temperature applications due lack of absorption. Major advantages from coatings compared to plane steel were not found. Plastics were found suitable materials in lower temperatures where adsorption exceeds absorption.
\end{abstract}

Keywords Carry over $\cdot$ Instrumenting $\cdot$ Recovery $\cdot$ Tubing $\cdot$ Sorption

\section{Introduction}

Gas analyzers based on ion mobility spectrometry (IMS) are used in various application areas such as medicine, process industry, security and research $([1,2]$. Due to its relative simplicity and ability to function at atmospheric pressure, IMS technology enables low-maintenance gas analysis even outside laboratory conditions. However, residual signal produced by the previously sampled gas results in so called carry-over effect that should be addressed in all applications. Recovery time, i.e. the time required for the system to clear out the carryover is dependent on analyzer materials, temperature, volume and control of the contaminating molecules. Recovery time can be improved by increasing the temperature, reducing surface area, and by optimizing material selection and filtration

M. Karjalainen

Markus.karjalainen@tuni.fi

1 Faculty of Medicine and Health Technology, Tampere University, Tampere, Finland

2 Olfactomics Oy, Tampere, Finland

3 Centre for Vascular Surgery and Interventional Radiology, Tampere University Hospital, Tampere, Finland methods utilized in the system ([3, 4]. These methods also have their downsides. Heating inherently increases the complexity and energy consumption of the system, reduces the number of applicable materials, and in some cases may also affect to the analyte composition by promoting chemical reactions. Minimizing the surface area by reducing of physical dimensions beyond a certain point further complicates the manufacturing of the system, and filtering potentially limits the range of detection.

With correct material selection, the recovery time of the system can be improved without energy draw and material limitations posed by heating to high temperatures. An ideal material would be flexible with minimal adsorption and absorption and with no degassing when heated up. Any material is a compromise between these factors. Typical materials in gas analysis are plastics such as fluoropolymers, metals or ceramics. Steel is typically used in high performance applications where minimal adsorption is critical because of its heat tolerance. In order to further improve the performance of steel, special coatings can also be deployed.

Our team focuses on the development of methods for the analysis of surgical smoke that is produced in electrosurgery operation to classify the tissue types being operated $([5,6]$. The $95 \%$ of the mass of surgical smoke is water and the remainder consists of volatile organic compounds (VOCs) 
and cellular debris [7]. Majority of VOCs and water is condensed into particulates $([8,9]$. This application area is particularly challenging as the combination of molecular and particulate matter easily condenses into the analytical system causing excessive carry-over effect. The particulates dominate the carry-over through dissolving back to the sample stream after the partial pressure in the stream is decreased below the vapor pressure of the molecules.

There is no literature on optimal material selection for sampling and analysis of surgical smoke. We chose seven common materials used in pneumatics and gas analyzers and evaluated their effect on the recovery times as a function of temperature by using differential mobility spectrometer (DMS).

From physicochemical perspective, we focused on different forms of sorption, namely adsorption, absorption, and desorption. We aimed to find out the sorption properties of the different materials by using the DMS for measuring carryover after sample introduction.

\section{Materials and methods}

\section{Tube materials and tubes}

We chose the most common materials used in VOC analyzers for the test tubes: polyether ether ketone (PEEK), polytetrafluoroethylene (PTFE), fluorinated ethylene propylene (FEP), polyethylene (PE), steel $316 \mathrm{~L}$, parylene C coated steel and Silconert ${ }^{\circledR}$ coated steel. The purpose of the Parylene and Silconert@ coatings is to reduce the adsorption on the steel tube surface. The length of the test tubes from each material was $30 \mathrm{~cm}$. The length of the test tubes was chosen to reflect the tubing of typical desktop-sized. Tubes had $4 \mathrm{~mm}$ Inner diameter (ID) except $3.2 \mathrm{~mm}$ PEEK-tube and additional $3 \mathrm{~mm}$ ID PTFE-tube.

Comparison of the materials was performed in the procedure and the setup described in Test setup 1. More detailed testing for the effect of temperature on the recovery time was performed for the PTFE tube with the procedure described in Test setup 2 .

\section{Test setup 1: Material comparison for recovery times.}

The test procedure consisted of two phases: sorption phase by contaminating smoke, and a desorption measurement phase. The smoke production setup consisted of a commercial electrosurgical knife (Itkacut MB350, Innokas Medical, Finland) attached to a stepper motor controlled xyz-stage modified from a 3D printer (REPRAP Mendel Prusa i3, Kitprinter3d, Spain) and a smoke evacuator (Surtron Evac, Quirumed, Spain). The smoke production setup is illustrated in Fig. 1 a). A similar setup has been used in previous studies, where the aim was to identify tissue types by DMS measurements of surgical smoke $([5,6,10]$. The setup in the desorption and the measurement phase consisted only the individual $30 \mathrm{~cm}$ long sample tubes and the DMS device (Envi-AMC, Environics Ltd., Mikkeli, Finland). An illustration of the desorption phase setup is presented in Fig. 1 b). Where six-channel tube holder was attached to setup in sorption phase and single tubes in the measurement phase.

For tube sorption phase, a fresh porcine kidney was cut with the electrosurgical knife. Kidney slices were around $1 \mathrm{~cm}$ thick in order to guarantee appropriate cutting depth for the knife. The sample tubes were cleaned with steam after each measurement for approximately two minutes and subsequent drying with pressurized air. This brought the sorption level (described in DMS Sensor section) back to the initial baseline value before the next sorption phase.

The movements of the diathermy knife used in the smoke production phase were controlled with the xyz-stage. The cuts made to the sample were $3 \mathrm{~mm}$ deep, $5 \mathrm{~mm}$ long. Blade width was $2.35 \mathrm{~mm}$. The surgical smoke evacuator was used to lead the smoke into the tubes as presented in Fig. 1 a). The smoke evacuator was immediately switched off once the smoke production ended to avoid driving excess ambient air through the sample tubes. The six-channel platform holding the sample tubes was then detached from the smoke production setup. The placement of the tubes in the six-channel platform was shuffled between the sorption cycles. Secondly, the sample tube order was shuffled in the measurement phase to take into account that some of the VOCs might desorb from the tubes between sorption and measurement. For reference, we sorbted two samples per material without particulates. This was performed with HEPA-filter between xyz-stage and test tubes.

The actual desorption measurement phase for each tube consisted of three stages:

1. The sample tube was connected to the sample input of the DMS device.

2. For the first $15 \mathrm{~s}$ of the 5-min measurement, clean air was measured to provide a baseline reference value for the desorption.

3. The airflow was changed to go through the sample tube for the rest of the measurement. The measurements were conducted in room temperature. Second set of measurements was conducted in a heating cabinet (MICRO, Temperature Applied Sciences (TAS), UK) where the tubes were warmed up at $70{ }^{\circ} \mathrm{C}$ for $5 \mathrm{~min}$ before the measurement was started. Desorption was approximated to follow first order dynamics, where the time constant $\tau$ equals approximately $63 \%$ reduction in the intensity from the beginning of the measurement phase. Half-life in first order rate equation compares to time constant with Eq. 1.

$t_{\S}=\tau * \ln (2)$ 

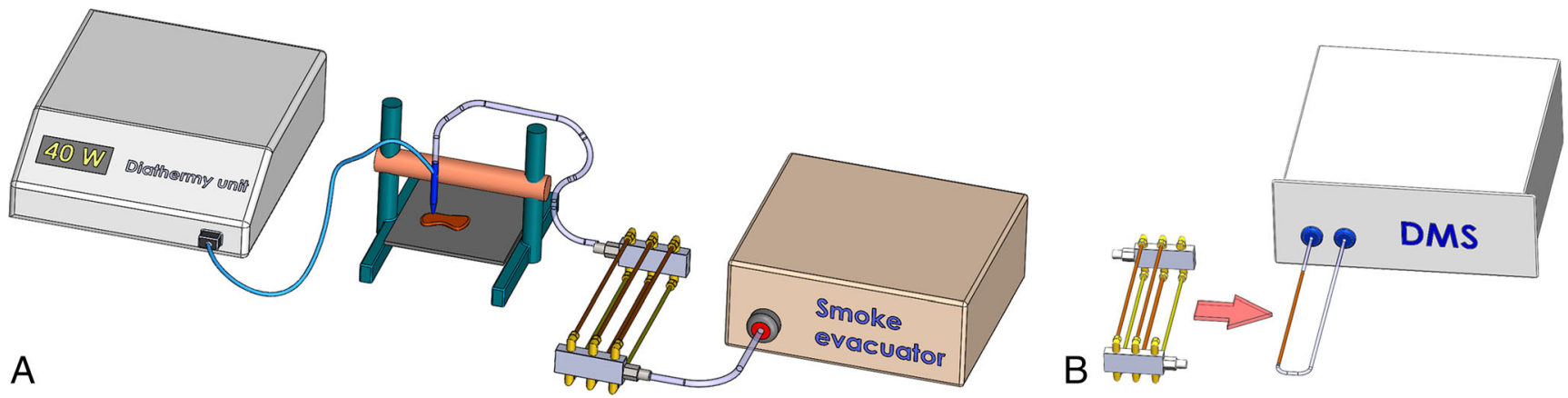

Fig. 1 Test setup 1: a) The sample tubes were connected into a flow divider that had six channels and the tubes were sorbted with surgical smoke from porcine renal tissue. b) Residual molecules were measured from each tube individually with the DMS

\section{Test setup 2: The Effect of Temperature on PTFE recovery.}

The second test setup consisted of a single PFTE-tube and a flow rate controller (AS2000, SMC Japan), which were heated to target temperature in a heat cabinet. The flow rate controller was included to simulate typical gas analyzer composition with tubes and other components. The surgical smoke sample was generated with electrosurgical knife and the xyz-stage as in Test setup 1. Since there was no need for changing tubes between sorption and desorption, the desorption phase was begun immediately after the sorption phase.

Figure 2 illustrates the test setup 2. Produced smoke was injected using flow injection principle. In the sorption phase, valve V1 was closed and valve V2 opened, resulting in a flow of $10 \mathrm{l} / \mathrm{min}$ from the diathermy system and additional $2 \mathrm{l} / \mathrm{min}$ flow from the clean air source. In the desorption phase valve $\mathrm{V} 1$ was open and valve V2 was closed causing $1.5 \mathrm{l} / \mathrm{min}$ flow through the sample tube from the clean air source. Excess $0.5 \mathrm{l} / \mathrm{min}$ clean air flow from $2 \mathrm{l} / \mathrm{min}$ was directed to the smoke evacuator.

\section{DMS sensor}

Sample tubes were measured with Envi-AMC® (Environics Oy, Finland), a Differential ion Mobility Spectrometer (DMS). It contains a radioactive Americium-241 source to ionize the volatile molecules in the sample gas and a sensor unit, which separates the ions with a high amplitude asymmetric radio frequency (RF) -electric field and a low amplitude DC compensation field. Two-dimensional spectrum is obtained by altering the strength RF of the electric fields and recording the amount of ionized molecules landing on the detector element at each pair of fields. The operation of the DMS is recently presented in detail elsewhere [11].

To assess the desorption, we performed a time series DMS sweep, where the aim was to particularly monitor the release and the amount of the sorbted heavy VOCs, instead of a normal sweep to measure a wide range of substances. For this purpose, the amplitude of the voltage generating the radio frequency field (Vrf) was kept nearly constant, at $450 \mathrm{~V}$ $451 \mathrm{~V}$. The reason for varying the amplitude by one volt was due to technical limitations of the DMS sensor. The compensation voltage $(\mathrm{Vc})$ was scanned from -1 to $5 \mathrm{~V}$ in steps of $0.3 \mathrm{~V}$, (Fig. 3). The time constant values were obtained at $\mathrm{Vc}=-0.3 \mathrm{~V}$.

We analyzed obtained recovery times with MannWhitney U-test (MWU) with 95\% confidence interval. This means that the statistical difference between the results was analyzed with the Mann Whitney $U$ test, and the presented result of significant statistical difference has a 95\% confidence interval. The confidence interval of $95 \%$ means that the null hypothesis (the distributions are the same i.e. no statistical difference) is rejected, if the $p$ value from the Mann Whitney $\mathrm{U}$
Fig. 2 The test setup for rapid adsorption-desorption cycle in elevated temperatures

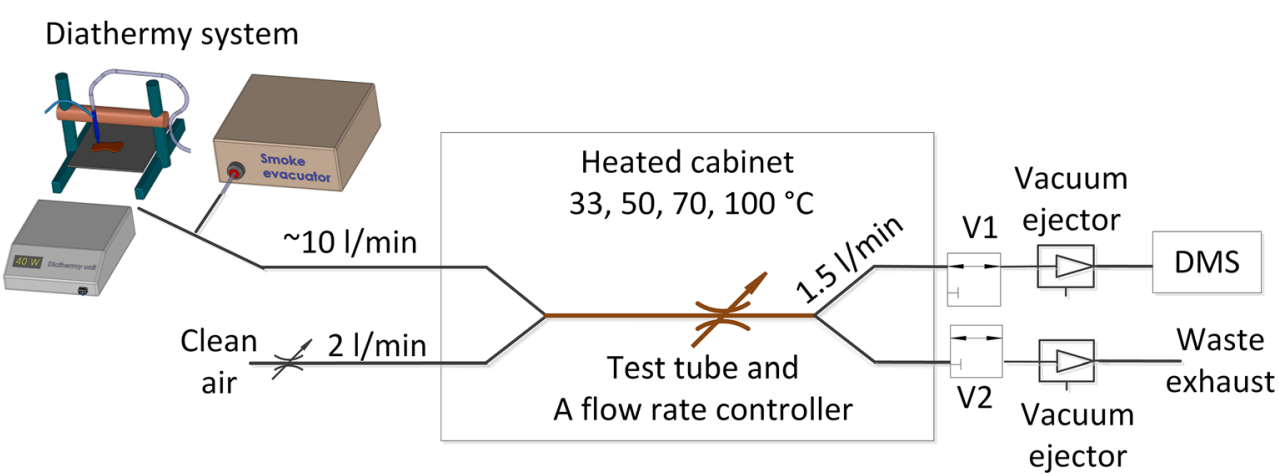




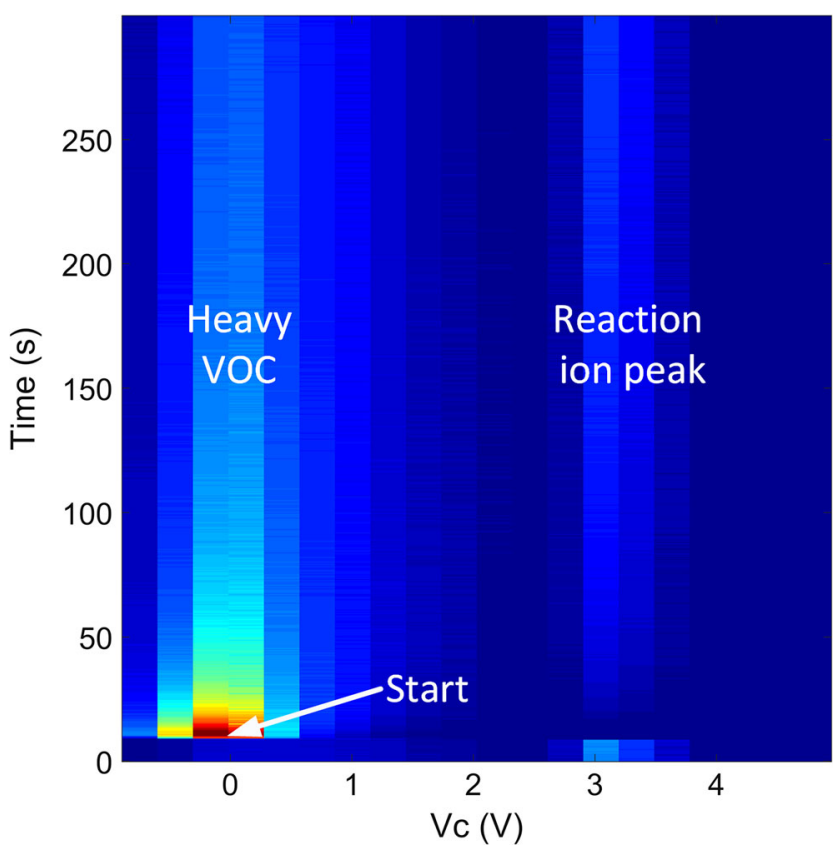

Fig. 3 Typical measurement spectrum from an individual desorption measurement. Scan consist two clusters, excessive undispersed heavy VOC cluster and reaction ion peak (RIP) consisting mainly of ionized water. The discontinuity at the beginning (start) is the moment when toggled to direct sample to DMS

test is under 0.05 . In practice this conveys the probability that the portrayed result of statistically significant difference is correct.

\section{Results}

Test setup 1: Material comparison for recovery times.

The results of the recovery time measurements for different materials are illustrated in Table 1. Shortest desorption time at room temperature was obtained with a smaller diameter $(3 \mathrm{~mm})$ PTFE tube. PEEK tube was next, but it also had a smaller inner diameter than other tubes (3.2 $\mathrm{mm}$ compared to the $4 \mathrm{~mm}$ in other materials). Uncoated steel tube had the third shortest recovery time. Silconert ${ }^{\circledR}$-coated and parylene-coated steel were nearly equal in terms of recovery time. Furthermore, the parylene-coating was partially detached during assemblies, which may explain the outliers between the test repetitions (Fig.4). The longest recovery time was obtained with PE-material. From the potential tube materials, diameter $(4 \mathrm{~mm})$ PTFE-tube had the worst recovery time. The sample number for FEP material is significantly lower than the rest of the materials, since the material arrived at the final stages of the measurement period. Box plots showing the distribution of the recovery time constants in room temperature are presented in Fig. 4.
We excluded PE-tubes from heated tests after two measurements, since heated PE itself was found to emit plasticizer molecules to the measurement gas. Heated $4 \mathrm{~mm}$ PTFE and FEP-tubes performed clearly worse than in unheated case. In opposite parylene-coated steel tube benefited from the heating the most and Silconert ${ }^{\circledR}$-coated and plain steel tube slightly. Box plots showing the distribution of the recovery time constants in the heated condition are presented in Fig. 5. The measurements in elevated temperature were conducted after the room temperature measurements, and due to limited equipment availability, the sample numbers had to be left lower. Filtering particulates before the sample tubes reduced both recovery times and signal levels. Precisely $63-81 \%$ reduction in recovery times and $13-47 \%$ reduction in signal peak. The only exception was parylene-coated steel, but this might be due to the coating that had damaged during repetitive testing.

(PEEK) polyether ether ketone, (PTFE) polytetrafluoroethylene, (FEP) fluorinated ethylene propylene, (PE) polyethylene, (S) steel 316 L, (PS) parylene C coated steel, (SS) Silconert ${ }^{\circledR}$ coated steel.

Data in boxplots preferably have $\mathrm{N}$ greater than 5 . Therefore, we excluded measurement with FEP: 30.5, 26.3, $27.7 \mathrm{~s}$ recovery times and $3 \mathrm{~mm}$ PTFE: $10.2,8.8,12.0,11.5 \mathrm{~s}$ from Fig. 4. In addition, from Fig. 5 FEP: 34.6, 35.5, 26.3, PVDF (3 mm) 6.9, $6.5 \mathrm{~s}$.

\section{Test setup 2: The Effect of Temperature on PTFE recovery.}

In test setup 2, the recovery time of a PTFE tube was measured in $33,50,70,100{ }^{\circ} \mathrm{C}$ ambient temperature. Recovery time constants for the heated PTFE tubes are presented in Fig. 6.

\section{Statistical analysis}

Mann-Whitney U-test was performed for the time constant values to assess the statistical validity of the results gained in this study. A 95\% confidence level (i.e. $p<0.05)$ was considered as the threshold for statistical significance. The results are presented in Table 2 and Table 3 for room temperature and $70{ }^{\circ} \mathrm{C}$ conditions, respectively. As seen in Table 2, statistically significant difference in the time constants was found between most material pairs. However, PE and PEEK were the only materials that have a statistically significant difference in the clearance time constants in room temperature compared to any other material. In the elevated temperature of $70{ }^{\circ} \mathrm{C}$, statistically relevant differences were only observed between some material pairs, but no material could be completely differentiated, as shown in Table 3. 
Table 1 Measured tube recovery times. $\tau$ is the recovery time constant in sec. MAX is maximum current signal in the beginning of the measurement. END is the remnant signal after 5 min of the measurement. $\mathrm{N}$ is the number of samples measured

\begin{tabular}{|c|c|c|c|c|c|c|c|c|c|c|c|c|}
\hline \multirow[b]{2}{*}{ Material } & \multicolumn{4}{|c|}{ Room temperature } & \multicolumn{4}{|c|}{$70^{\circ} \mathrm{C}$} & \multicolumn{4}{|c|}{ HEPA-filtered } \\
\hline & $\begin{array}{l}\tau \\
(s)\end{array}$ & $\begin{array}{l}\text { MAX } \\
\text { (pA) }\end{array}$ & $\begin{array}{l}\text { END } \\
\text { (pA) }\end{array}$ & $\mathbf{N}$ & $\tau(s)$ & MAX (pA) & $\begin{array}{l}\text { END } \\
\text { (pA) }\end{array}$ & $\mathbf{N}$ & $\tau(s)$ & $\begin{array}{l}\text { MAX } \\
\text { (pA) }\end{array}$ & $\begin{array}{l}\text { END } \\
\text { (pA) }\end{array}$ & $\mathbf{N}$ \\
\hline PTFE, 3 mm & 10.9 & 163 & 23.5 & 4 & 6.69 & 208 & 51.2 & 2 & - & - & - & - \\
\hline PEEK, $3.2 \mathrm{~mm}$ & 16.2 & 314 & 62.8 & 21 & 15.2 & 305 & 98.7 & 6 & 6.00 & 202 & 82.4 & 2 \\
\hline $\mathrm{S}, 4 \mathrm{~mm}$ & 19.4 & 290 & 63.6 & 18 & 17.8 & 280 & 90.9 & 6 & 6.00 & 153 & 92.4 & 2 \\
\hline FEP, $4 \mathrm{~mm}$ & 27.7 & 239 & 33.4 & 3 & 34.6 & 298 & 76.2 & 3 & 7.38 & 179 & 70.3 & 2 \\
\hline PS, 4 mm & 30.0 & 222 & 63.6 & 18 & 14.1 & 274 & 86.3 & 6 & 35.1 & 189 & 89.0 & 2 \\
\hline $\mathrm{SS}, 4 \mathrm{~mm}$ & 31.2 & 381 & 66.9 & 18 & 30.0 & 352 & 90.7 & 6 & 10.4 & 332 & 83.1 & 2 \\
\hline PTFE, 4 mm & 37.9 & 319 & 71.5 & 20 & 49.9 & 294 & 89.9 & 8 & 7.15 & 210 & 75.9 & 2 \\
\hline $\mathrm{PE}, 4 \mathrm{~mm}$ & 91.4 & 221 & 125 & 18 & $\mathrm{NaN}$ & 459 & 425 & 2 & - & - & - & - \\
\hline
\end{tabular}

\section{Discussion}

\section{Recovery time constants}

Shortest recovery time for unheated materials was achieved with tubes with smaller diameter, PEEK and PTFE. For the tubes with a larger inner diameter, $4 \mathrm{~mm}$, pure steel tube had the shortest recovery time. In the heated experiment, parylene coated steel performed best. Silconert coating performed worse than pure steel, but may perform better in higher temperatures, since the recommended temperature range of the manufacturer goes up to $450^{\circ} \mathrm{C}$. This could explain the reason why Silconert-coated steel was inferior in terms of recovery times when compared to uncoated steel. The difference between the two materials decreases along with rising temperature and it is possible that Siclonert-coating performs superiorly when temperature is elevated significantly above those used in our study. As demonstrated by these results the inner diameter is a noteworthy factor in terms of recovery time. These results are in line with the results of Dowker and

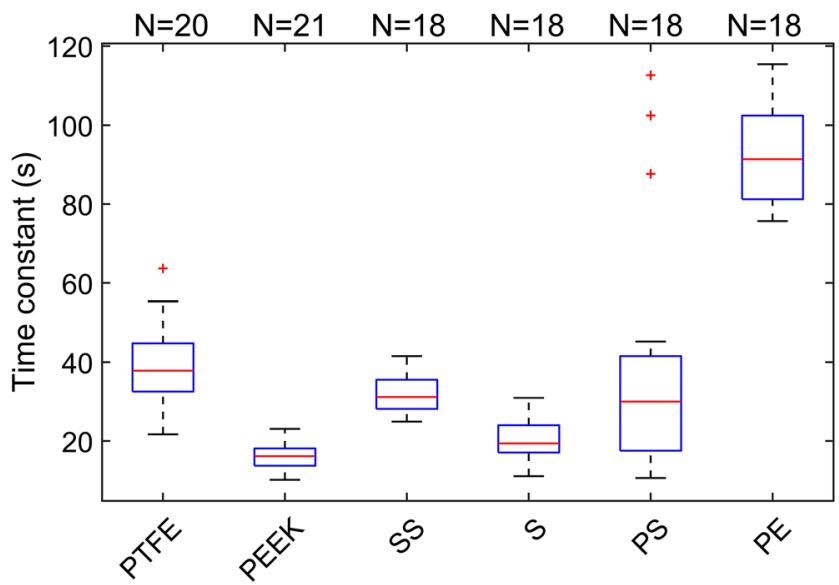

Fig. 4 Distributions of the recovery time constants at room temperature. $\mathrm{N}$ is the number of test repetitions
Hardwick [12], where the recovery time was found being dependent on the cross-sectional area of the tubes. In addition, Moschou et al. have showed that the recovery time correlates with the sample flow speed and water evaporation speed correlating sample flow speed [13].

\section{Summary about sorption related factors}

Our results showed unexpected effect in the recovery times for PTFE between the heated and the unheated conditions (Fig. 4 and Fig. 5). The recovery times were somewhat slower in the heated test compared to the unheated. In the first experiment, we heated the tubes after the sorption phase for five minutes. This heating time could provide moment for adsorption. The heating increased permeability of PTFE and thus absorption into the tube material due to elevated temperature and relatively long five-minute diffusion time. This could be significant compared to decreased adhesion to the heated plastic surface.

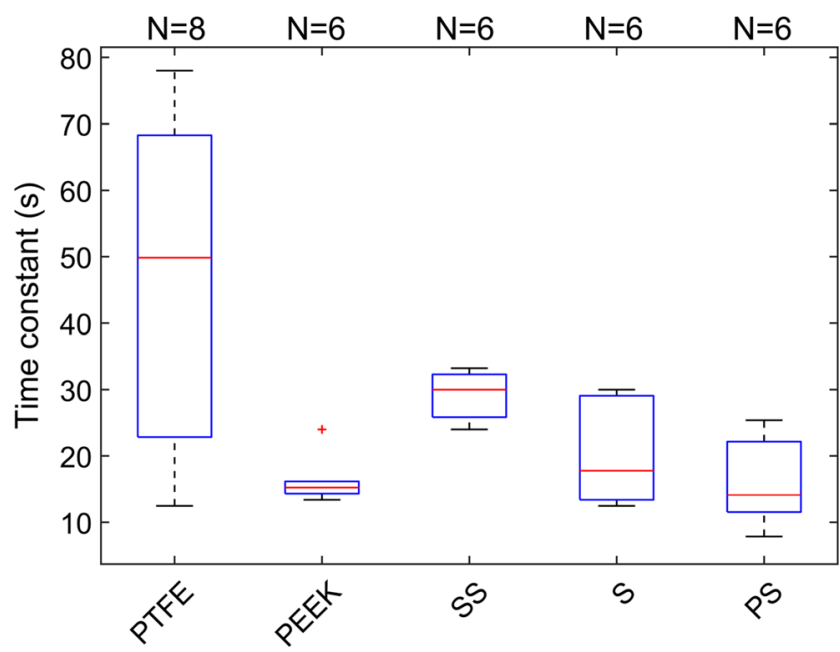

Fig. 5 Distributions of the recovery time constants at $70^{\circ} \mathrm{C}$ temperature. $\mathrm{N}$ is the number of measurements included in the analysis 


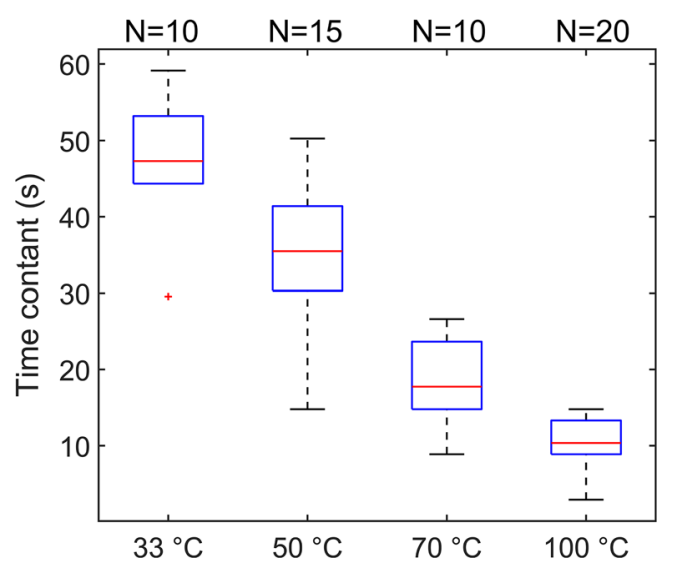

Fig. 6 Recovery time constant of a PTFE tube in various temperatures. Differences were statistically significant between all temperatures, according to Mann-Whitney U test with $95 \%$ confidence interval

The effect of increased absorption is also supported by the results obtained in additional PTFE heating test. As shown in Fig. 6, increase in temperature decreased the recovery time, as opposed to Fig. 5, where the tubes had the five-minute heating and an even longer assembly-disassembly period. In the second test (Fig. 6), tubes had only few second transition times and no assembly time. As metals have lower permeability than plastics, this could also explain why metal tubes recovered faster than plastic tube when heated.

In general, the recovery time of a tube depends on the desorption speed and the amount of the contaminating sorption, consisting absorption and adsorption. Adsorption consists of physisorption and chemisorption. We interpreted these results only through physisorption, since we assumed chemisorption to be irrelevant, having too strong bond energies to match these desorption kinetics (Grinham and Chew 2017). Energy in hydrogen bonds in water falls between physisorption and chemisorption. Therefore, steam is convenient for removal of physisorpted molecules. Similarly, we excluded competitive adsorption models, which could be fitted to data in respect of competition between different bond strengths in molecule alignment on surface (Singh et al. 2019). The exclusion was made based on the limited theoretical background and references.
Table 3 The result matrix of the statistical analysis based on the recovery times of the tubes at $70{ }^{\circ} \mathrm{C}$. Table presents P-values, where bolded values indicate a statistically significant difference (MWU 95\%CI)

\begin{tabular}{lllllll}
\hline & SS & S & PS & FEP & PTFE & PEEK \\
\hline SS & & 0.0649 & $\mathbf{0 . 0 0 4 3}$ & 0.2619 & 0.4136 & $\mathbf{0 . 0 0 4 3}$ \\
S & - & & 0.3095 & 0.0952 & 0.0626 & 0.4848 \\
PS & - & - & & $\mathbf{0 . 0 2 3 8}$ & $\mathbf{0 . 0 2 9 3}$ & 0.5887 \\
FEP & - & - & - & & 0.6303 & $\mathbf{0 . 0 2 3 8}$ \\
PTFE & - & - & - & - & & $\mathbf{0 . 0 2 9 3}$ \\
PEEK & - & - & - & - & - & \\
\hline
\end{tabular}

The quantity of sorption is the sum of adsorption and absorption. Adsorption is dependent on the surface area, surface free energy of the surface and inversely on the vapor pressure of the adsorpted molecule. [14] In contrast, absorption depends on solubility, permeability and diffusion, $([15,16]$, and the quantity of diffused molecules depends on exposure time (Fig.7). Solubility and diffusion are exponentially dependent on temperature [16] [15]. A rule of thumb is that every $10{ }^{\circ} \mathrm{C}$ increase in temperature doubles the permeability and therefore absorption as well. The surface free energy, unlike vapor pressure, does not increase dramatically in relation to temperature [17]. Thus, adsorption decreases on elevating temperatures.

The surface free energies of the materials used in this study have substantial differences that can partly explain the changes in recovery times. According to acid-base theorem, surface free energy can be approximated by the single component model where it is divided into dispersive (van der Waals type) and acid and base components [18] [19]. Eq. 2 shows the model for total surface free energy

$\gamma^{T o t .}=\gamma^{L W}+2 \sqrt{\gamma^{+} \gamma^{-}}$

, where $\gamma^{\mathrm{LW}}$ is the van der Waals component, $\gamma$ - is the electron donor component, and $\gamma+$ is the electron acceptor component.
Table 2 The result matrix of a statistical analysis based on the recovery times of the tubes at room temperature. Table presents $P$-values, where bolded values indicate a statistically significant difference with Mann-Whitney U test with $95 \%$ confidence interval

\begin{tabular}{llllllllr}
\hline & SS & S & PS & PE & FEP & PTFE & PTFE 3 mm & \multicolumn{2}{l}{ PEEK } \\
\hline SS & & $<\mathbf{1 0}^{-5}$ & 0.7042 & $<\mathbf{1 0}^{-5}$ & 0.1912 & $\mathbf{0 . 0 1 8 6}$ & $\mathbf{0 . 0 0 2 5}$ & $<\mathbf{1 0}^{-5}$ \\
S & - & & 0.0597 & $<\mathbf{1 0}^{-5}$ & $\mathbf{0 . 0 2 6 9}$ & $<\mathbf{1 0}^{-5}$ & $\mathbf{0 . 0 0 4 3}$ & $\mathbf{0 . 0 0 7 1}$ \\
PS & - & - & & $\mathbf{0 . 0 0 0 1}$ & 0.9599 & 0.1321 & $\mathbf{0 . 0 0 4 3}$ & $\mathbf{0 . 0 0 0 8}$ \\
PE & - & - & - & & $\mathbf{0 . 0 0 7 7}$ & $<\mathbf{1 0}^{-5}$ & $\mathbf{0 . 0 0 2 5}$ & $<\mathbf{1 0}^{-5}$ \\
FEP & - & - & - & - & & 0,0912 & 0,0571 & $\mathbf{0 , 0 0 6 8}$ \\
PTFE & - & - & - & - & - & & $\mathbf{0 , 0 0 2 2}$ & $\mathbf{0 , 0 0 0 0}$ \\
$3 \mathrm{~mm}$ & - & - & - & - & - & - & & $\mathbf{0 . 0 0 3 4}$ \\
PEEK & - & - & - & - & - & - & - & \\
\hline
\end{tabular}




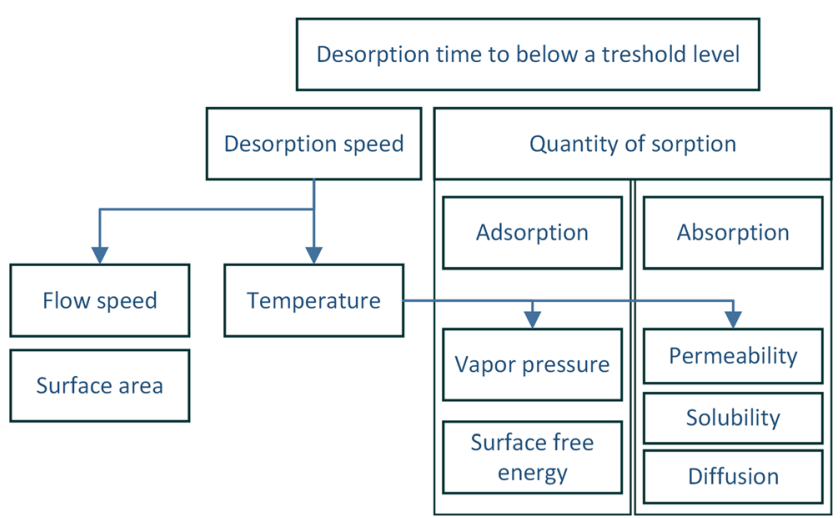

Fig. 7 Estimation schematic for major affecting parameters for tube recovery time

Surface free energy components for steel are $\gamma^{\mathrm{LW}}=$ $38.7 \mathrm{~mJ} / \mathrm{m}^{2}, \gamma-=39.1 \mathrm{~mJ} / \mathrm{m}^{2}$, and $\mathrm{y}+=1.4 \mathrm{~mJ} / \mathrm{m}^{2}$ resulting in total surface free energy $y^{\text {tot }}$ of $54 \mathrm{~mJ} / \mathrm{m}^{2}$. For PTFE $\gamma^{\mathrm{LW}}=$ $18.1 \mathrm{~mJ} / \mathrm{m}^{2}, \gamma-=2.2 \mathrm{~mJ} / \mathrm{m}^{2}$, and $\gamma+=0.1 \mathrm{~mJ} / \mathrm{m}^{2}$, thus yielding $\mathrm{y}^{\text {tot }}=19 \mathrm{~mJ} / \mathrm{m}^{2}[20]$. According to a single component model parylene has total surface free energy of $27.64 \mathrm{~mJ} / \mathrm{m}^{2}$ [21], FEP $16.9-22.7 \mathrm{~mJ} / \mathrm{m}^{2}$ [22], PEEK $42.4-49.8 \mathrm{~mJ} / \mathrm{m}^{2}$ [23], and PE $31 \mathrm{~mJ} / \mathrm{m}^{2}$ [24].

Since increase in surface free energy increases adsorption, we can conclude that softer materials (less surface energy) adsorb less, but due to the material porosity, they absorb more, especially in higher temperatures. For example, $\mathrm{H}_{2} \mathrm{O}$ permeability for PTFE is at $20{ }^{\circ} \mathrm{C} 0.0045 \mathrm{gmm} / \mathrm{m}^{2}$ day, at $40{ }^{\circ} \mathrm{C}$ $0.0174 \mathrm{gmm} / \mathrm{m}^{2}$ day, and at $80{ }^{\circ} \mathrm{C} 0.241 \mathrm{gmm} / \mathrm{m}^{2}$ day [25, 26]. For metals, the absorption is insignificant.

In addition to surface free energy, the flow speed of the sample and carrier gas is a factor that contributes to the recovery time. More specifically, the flow speed affects to the desorption rate. Lyulin and Kabov described an evaporation correlation as Eq. 3 [27],

$Q=1.5^{*} 10^{-4} T^{1.82} U_{g}^{0.147}$

Where $\mathrm{Q}$ is the mass flow, $\mathrm{T}$ is the temperature in Celsius and $\mathrm{U}_{\mathrm{g}}$ is the mass flow in a test chamber. This would imply that the difference between tubes having 4 and $2 \mathrm{~mm}$ inner diameter (id) is only $23 \%$, but temperature elevation from 20 to $40{ }^{\circ} \mathrm{C}$ produce a 3.5 times faster response. On the contrary [13], studied evaporation where the results indicated that $2 \mathrm{~mm}$ (id) tube recovers 4 times faster than a $4 \mathrm{~mm}$ tube. This is also closer to the results reported in a study by [12]. We observed a 3.5-fold increase in recovery time, in unheated situation and 7.4-fold increase in heated situation between 4 and $3 \mathrm{~mm}$ PTFE tubes being clearly larger than expected.

Figure 7 presents major affecting parameters for tube recovery time. The recovery time depends on desorption speed and the amount of sorption. The sorption can be divided to adsorption and absorption, where vapor pressure and surface free energy affects to adsorption. Permeability, solubility and diffusion affects to absorption. Desorption speed is affected by airflow speed, tube diameter and surface area. In addition, temperature affects to desorption, adsorption and absorption.

\section{Limitations}

The key limitation of this study is the relatively small sample size of the different materials in the test setups. The sample size restricted the ability to draw statistically valid conclusions regarding the recovery times between some of the materials. With substantially more measurements, statistically significant differences between more tubing materials could most likely be seen. In addition, some of the parylene coatings partially detached during assembly and might cause some additional adhesion due to the increased surface area. These tests revealed direct desorption time constants for a specific application. However, temperature programmed desorption (TPD) is another possible approach. Using TDB all sorpted substances are desorpted and measured, which should decrease measurement uncertainties.

\section{Conclusions}

Optimal tubes should have maximal flow speed, minimal surface area, and minimal adsorption and absorption. Because increase in temperature decreases adsorption but increases absorption and since plastics absorb considerably, there should, in principle be an optimal temperature for the plastics. The exposure time may play a major role in this feature because the adsorption is faster than absorption. Therefore, short exposure times would elevate the optimal temperature for plastics. For metal tubes, the absorption is minimal and therefore there may not be such an optimal temperature. In this case, increase in temperature explicitly improves the performance by decreasing the amount of contamination.

Based on our results, we suggest that people working with gas analyzers would:

1. Use tubes with minimal inner diameter

2. Avoid using PE

3. Use PEEK or fluoropolymers in moderate temperature and demanding applications

4. Use metal tubing's in high performance and high temperature applications

Authors' contributions Markus Karjalainen, experiment design, data collection, data processing, manuscript writing,

Anton Kontunen, experiment design, data collection, data processing, manuscript writing, manuscript revision.

Meri Mäkelä, data collection, manuscript writing.

Osmo Anttalainen, design of experiments, manuscript writing, revision. 
Antti Vehkaoja, manuscript writing, manuscript revision.

Niku Oksala, manuscript writing, manuscript revision, support.

Antti Roine, experiment design, manuscript writing, manuscript revision, support.

Funding information This study was financially supported (or partly supported) by The Finnish Cultural Foundation, Pirkanmaa Regional Fund; by The Finnish Foundation for Technology Promotion; by the Competitive State Research Financing of the Expert Responsibility area of Tampere University Hospital (9s045, 151B03, 9T044, 9U042, 150618, 9V044 and 9X040, 9AA057); by Competitive funding to strengthen university research profiles funded by Academy of Finland, decision number 292477; and by Tampereen Tuberkuloosisäätiö (Tampere Tuberculosis Foundation).

\section{Compliance with ethical standards}

Conflict of interest Markus Karjalainen, Anton Kontunen, Meri Mäkelä, Osmo Anttalainen, Niku Oksala and Antti Roine are employed by Olfactomics Ltd. Markus Karjalainen, Anton Kontunen, Osmo Anttalainen, Niku Oksala and Antti Roine are shareholders of Olfactomics Oy.

Declarations The funder provided support in the form of salaries for authors M.K., A.K., but did not have any additional role in the study design, data collection and analysis, decision to publish, or preparation of the manuscript. The specific roles of these authors are articulated in the 'author contributions' section. Olfactomics Ltd. did not provide any funding for the study and did not play any role in the study design.

Open Access This article is licensed under a Creative Commons Attribution 4.0 International License, which permits use, sharing, adaptation, distribution and reproduction in any medium or format, as long as you give appropriate credit to the original author(s) and the source, provide a link to the Creative Commons licence, and indicate if changes were made. The images or other third party material in this article are included in the article's Creative Commons licence, unless indicated otherwise in a credit line to the material. If material is not included in the article's Creative Commons licence and your intended use is not permitted by statutory regulation or exceeds the permitted use, you will need to obtain permission directly from the copyright holder. To view a copy of this licence, visit http://creativecommons.org/licenses/by/4.0/.

\section{References}

1. Armenta S, Alcala M, Blanco M (2011) A review of recent, unconventional applications of ion mobility spectrometry (IMS). Anal Chim Acta 703(2):114-123

2. Röck F, Barsan N, Weimar U (2008) Electronic nose: current status and future trends. Chem Rev 108(2):705-725

3. Giles K, Gordon D (2010) A new conjoined RF ion guide for enhanced ion transmission. In: Proc. 58th ASMS Conf. Mass spectrometry and allied topics

4. Guttman M, Wales TE, Whittington D, Engen JR, Brown JM, Lee KK (2016) Tuning a high transmission ion guide to prevent gasphase proton exchange during H/D exchange MS analysis. J Am Soc Mass Spectrom 27(4):662-668

5. Haapala I, Karjalainen M, Kontunen A et al (2019) Identifying brain tumors by differential mobility spectrometry analysis of diathermy smoke. J Neurosurg 1:1-7
6. Sutinen M, Kontunen A, Karjalainen M, Kiiski J, Hannus J, Tolonen T, Roine A, Oksala N (2019) Identification of breast tumors from diathermy smoke by differential ion mobility spectrometry. Eur J Surg Oncol 45(2):141-146

7. Ulmer BC (2008) The hazards of surgical smoke. AORN J 87(4): 721-738

8. Brüske-Hohlfeld I, Preissler G, Jauch K-W, Pitz M, Nowak D, Peters A, Wichmann HE (2008) Surgical smoke and ultrafine particles. J Occup Med Toxicol 3(1):31. https://doi.org/10.1186/1745-6673-3-31

9. Karjalainen M, Kontunen A, Saari S, Rönkkö T, Lekkala J, Roine A, Oksala N (2018) The characterization of surgical smoke from various tissues and its implications for occupational safety. PLoS One 13(4): e0195274. https://doi.org/10.1371/journal.pone.0195274

10. Kontunen A, Karjalainen M, Lekkala J, Roine A, Oksala N (2018) Tissue identification in a porcine model by differential ion mobility spectrometry analysis of surgical smoke. Ann Biomed Eng 46(8): 1091-1100

11. Anttalainen O, Puton J, Kontunen A et al (2019) Possible strategy to use differential mobility spectrometry in real time applications. Int J Ion Mobil Spectrom:1-8

12. Dowker K, Hardwick K (2008) RR-635 effect of tubing type on gas detector sampling systems, research reports of health and safety. Executive, UK https://www.hse.gov.uk/research/rrhtm/rr635.htm,

13. Moschou P, de Croon M, Van Der Schaaf J, Schouten JC (2013) Liquid flow rate effects during partial evaporation in a falling film micro contactor. Chem Eng Process Process Intensif 69:95-103

14. Do DD, others (1998) Adsorption analysis: equilibria and kinetics. Imperial college press London

15. Mitchell GD (2000) A review of permeation tubes and permeators. Sep Purif Methods 29(1):119-128

16. Wang X, Wolfbeis OS (2014) Optical methods for sensing and imaging oxygen: materials, spectroscopies and applications. Chem Soc Rev 43(10):3666-3761

17. Rulison C (2006) Effect of temperature on the surface energy of solids. COATING-ST Gall 39:52

18. Van Oss CJ, Good RJ, Chaudhury MK (1986) The role of van der Waals forces and hydrogen bonds in hydrophobic interactions between biopolymers and low energy surfaces. J Colloid Interface Sci 111:378-390

19. Rulison C (1999) So you want to measure surface energy. Charlotte $\mathrm{NC}$ ( $\mathrm{cf} \mathrm{p}$ 99)

20. Rosmaninho R, Rizzo G, Müller-Steinhagen H, Melo LF (2003) Study of the influence of bulk properties and surface tension on the deposition process of calcium phosphate on modified stainless steel

21. Chindam C, Lakhtakia A, Awadelkarim OO (2015) Surface energy of Parylene C. Mater Lett 153:18-19

22. Ebnesajjad S, Ebnesajjad C (2013) Surface treatment of materials for adhesive bonding. William Andrew

23. Heimer S, Schmidlin PR, Stawarczyk B (2016) Effect of different cleaning methods of polyetheretherketone on surface roughness and surface free energy properties. J Appl Biomater Funct Mater 14(3):e248-e255

24. Fox HW, Zisman WA (1952) The spreading of liquids on lowenergy surfaces. III Hydrocarbon surfaces J Colloid Sci 7:428-442

25. Massarweh NN, Cosgriff N, Slakey DP (2006) Electrosurgery: history, principles, and current and future uses. J Am Coll Surg 202(3): 520-530

26. Massey LK (2003) Permeability properties of plastics and elastomers: a guide to packaging and barrier materials. William Andrew

27. Lyulin YV, Kabov OA (2013) Measurement of the evaporation mass flow rate in a horizontal liquid layer partly opened into flowing gas. Tech Phys Lett 39(9):795-797

Publisher's note Springer Nature remains neutral with regard to jurisdictional claims in published maps and institutional affiliations. 